\title{
Gabriel Chappuys, Les Facétieuses Journées
}

\section{Filippo Fonio}

\section{(2) OpenEdition}

\section{Journals}

\section{Edizione digitale}

URL: http://journals.openedition.org/studifrancesi/35898

DOI: 10.4000/studifrancesi.35898

ISSN: 2427-5856

\section{Editore}

Rosenberg \& Sellier

\section{Edizione cartacea}

Data di pubblicazione: 1 juillet 2005

Paginazione: 147-148

ISSN: 0039-2944

\section{Notizia bibliografica digitale}

Filippo Fonio, «Gabriel Chappuys, Les Facétieuses Journées», Studi Francesi [Online], 145 (XLIX | I) |

2005, online dal 30 novembre 2015, consultato il 18 avril 2021. URL: http://journals.openedition.org/ studifrancesi/35898; DOI: https://doi.org/10.4000/studifrancesi.35898 


\title{
Gabriel Chappuys, Les Facétieuses Journées
}

\author{
Filippo Fonio
}

\section{NOTIZIA}

GABRIEL CHAPPUYS, Les Facétieuses Journées, édition établie et annotée par MICHEL BIDEAUX, Paris, Honoré Champion, («Textes de la Renaissance - Série Contes et Nouvelles de la Renaissance», 77), 2003, pp. 897.

Questa edizione delle Facétieuses Journées, raccolta di novelle proposta da Gabriel Chappuys, è la prima dopo quella del 1584 presso Jean Houzé stampatore parigino. Nato ad Amboise forse nel 1546, Chappuys trascorre gli anni della gioventù in collegio a Tours (di qui l'attributo Tourangeau con il quale Chappuys talvolta si designa o viene designato, e che ha tratto in inganno i biografi circa il luogo della sua nascita). Precettore a Tourville in Normandie, si trasferisce quindi a Lione, dove resta nel periodo 1576-1583, iniziando la propria attività professionale di traduttore: “Activité féconde et variée, tributaire toutefois des besoins des imprimeurs qui lui commandent les livres qui plaisent au public", p. 17. In questi anni di contatti con l'ambiente letterario e i circoli umanistici lionesi, Chappuys traduce in particolare poemi e dialoghi italiani sul modello del Cortegiano, opere devozionali, storiografiche, compilazioni, dallo spagnolo e dal latino oltre che dall'italiano. Nel periodo lionese è da collocarsi un soggiorno in Italia presso la corte di Emanuele Filiberto, verosimilmente fra 1574 e 1576. La costante ricerca di un protettore-mecenate che lo sottragga alla febbrile attività di traduttore (alla fine della sua carriera si possono forse contare un centinaio di titoli) lo vede a Parigi dal 1583 al 1589 circa, dove viene nominato storiografo reale (ruolo che era appartenuto al defunto Belleforest) per intercessione di Du Verdier e del Père Auger, e probabilmente interprete dall'italiano. Traduce d'ora in avanti per lo più opere devozionali, anche per guadagnarsi il favore di Enrico III, per seguire il quale fa ritorno a Tours nel 1589. All'inizio del regno di Enrico IV Chappuys, 
pur fervente cattolico, è nominato Garde de la Bibliothèque du Roi, titolo conservato anche sotto Luigi XIII. Muore forse nel 1612-13.

L'incessante attività di Chappuys lo porterà a essere, a detta tanto dei contemporanei quanto dei critici odierni impegnati nel tracciare un bilancio del panorama della traduzione francese a cavallo fra XVI e XVII secolo, "un des meilleurs italianisants de son temps", p. 156. Non può dirsi altrettanto riguardo ai giudizi espressi sulle Facétieuses Journées da parte di un'epoca in linea con la Deffence di Du Bellay, scettica nei confronti della traduzione letteraria. Alla novella di origine italiana, anche per un diffuso anti-italianismo, si tende a preferire quella romanzesca di derivazione spagnola e il romanzo sentimentale. Queste sono alcune delle ragioni dell'insuccesso della raccolta di Chappuys, oltre probabilmente - come suggerisce l'editore - al discutibile valore letterario.

Spesso ritenute opera originale dalla critica, Les Facétieuses Journées sono sostanzialmente (cinquantatre novelle su cento, più la maggior parte dei testi-soglia) una traduzione delle Cento novelle scelte, compilazione curata dallo stampatore veneziano Francesco Sansovino, in particolare della quarta edizione del 1566. Il modello scelto dal Sansovino è boccacciano: cento novelle narrate nel corso di dieci giornate da un"'allegra brigata" di giovani, l'elezione di un re al giorno, la presenza stessa e il modello della cornice, benché molto ridimensionata per importanza e per estensione. Oltre a essere di ispirazione boccacciana, l'antologia curata dal Sansovino comprende per lo più novelle dal Decameron e da Bandello, ma anche da Masuccio, dal Pecorone, dal Novellino, da Parabosco, dall'Erasto (derivato dal Libro dei Sette Savi), da Straparola, Brevio, Firenzuola e altri. Il Sansovino apporta modifiche alle novelle secondo i dettami controriformisti della censura preventiva e conferisce una patina linguistica uniforme ai testi, ordinando le composizioni nell'ambito della raccolta in base a criteri di unità e variatio. Chappuys scarta dall'antologia sansoviniana tutte le novelle tratte dal Boccaccio: $i$ testi già proposti in versione francese, come in questo caso nella traduzione di Le Maçon edita nel 1545, sono infatti rimpiazzati da composizioni del Firenzuola (del quale forse Chappuys aspirava a farsi mediatore in Francia), di Arlotto, del Parabosco, del Doni, di Straparola. Rispetto al Sansovino viene attenuato il tono di «anthologie normative plutôt que représentative», p. 114, di modo tale che l'opera di Chappuys risulta «un panorama de la novellistica antérieure à 1560 inséré dans le cadre choisi par le maître du genre: Boccace, absent des récits pris isolément, mais omniprésent dans le recueil», p. 144.

4 Su cento novelle, ottantasei sono di sicura derivazione italiana (di cui settantuno tradotte per la prima volta in francese da Chappuys), magari ricontestualizzate in vario modo per renderle più adatte a un pubblico francese. Quattordici novelle restano di origine incerta allo stato attuale delle ricerche; alcuni studiosi ritengono trattarsi di adattamenti da modelli italiani o spagnoli non ancora individuati, altri come lo stesso Bideaux propendono per considerarle composizioni originali di Chappuys. Gli argomenti in favore di questa teoria sono tanto questioni di onomastica, ambientazione e in generale fattori contestuali, quanto il tono meno 'faceto' e il gusto particolare di queste quattordici novelle, vicine al moralismo del genere delle histoires tragiques (che si sviluppa in Francia dalla seconda metà del XVI sec. anche sull'onda di alcune traduzioni francesi di Bandello. Cfr. in proposito JEAN BALSAMO, Les rencontres des Muses: italianisme et anti-italianisme en France à la fin de XVI siècle, Paris, Champion, 1992, p. 286). Queste composizioni si presentano «lourdes de commentaires moralisants, elles imputent le 
destin malheureux des protagonistes, non à l'instable Fortune, mais à la faiblesse et, plus souvent encore, à la méchanceté humaines», p. 77. Alle fonti e agli antecedenti di alcune novelle è dedicata un'appendice che individua fra l'altro le tecniche di adattamento e riscrittura messe in atto da Chappuys (una delle costanti è il tentativo di ottenere effetti di copia, in particolare mediante un uso esasperato di binomi sinonimici, in accordo ai dettami della retorica del tempo).

5 In linea con le teorie poetiche di Ronsard e della Pléiade, nonché sul modello della musa cristiana di Du Bartas, Chappuys aggiunge allo scopo tradizionale della novellistica, il diletto del lettore (evidente in questo caso già dal titolo, ispirato dalle Facétieuses Nuits, traduzione francese delle Piacevoli notti di Straparola), quello della diffusione di testi non ancora tradotti, oltre a finalità morali e religiose.

6 L'edizione è corredata da un'introduzione che comprende notizie biografiche su Gabriel Chappuys, uno studio sui criteri di composizione e le fonti della raccolta, oltre ad alcune schede sull'attività di traduttore di Chappuys e sulla natura degli italianismi presenti nelle novelle. Seguono una dettagliata bibliografia, una nota al testo e la riproduzione dei testi-soglia, l'edizione delle Facétieuses Journées, un glossario e gli indici. 